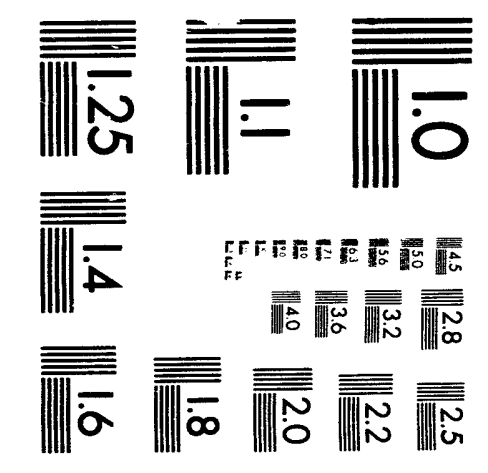




\section{Conf $-93: 107--16$ \\ LBL-34813 \\ UC-414}

\section{(B) Lawrence Berkeley Laboratory UNIVERSITY OF CALIFORNIA}

Physics Division

Presented at the IEEE Nuclear Science Symposium,

San Francisco, California, November 2-5, 1993,

and to be published in the Proceedings

\section{Amorphous Silicon Pixel Layers with Cesium} Iodide Converters for Medical Radiograph"'

T. Jing, C.A. Goodman, G. Cho, J. Drewery, W.S. Hong, H. Lee, S.N. Kaplan, A. Mireshghi, V. Perez-Mendez, and D. Wildermuth

$$
\begin{aligned}
& \text { OEC } 13 \text { isgo } \\
& \text { OSTI }
\end{aligned}
$$

November 1993

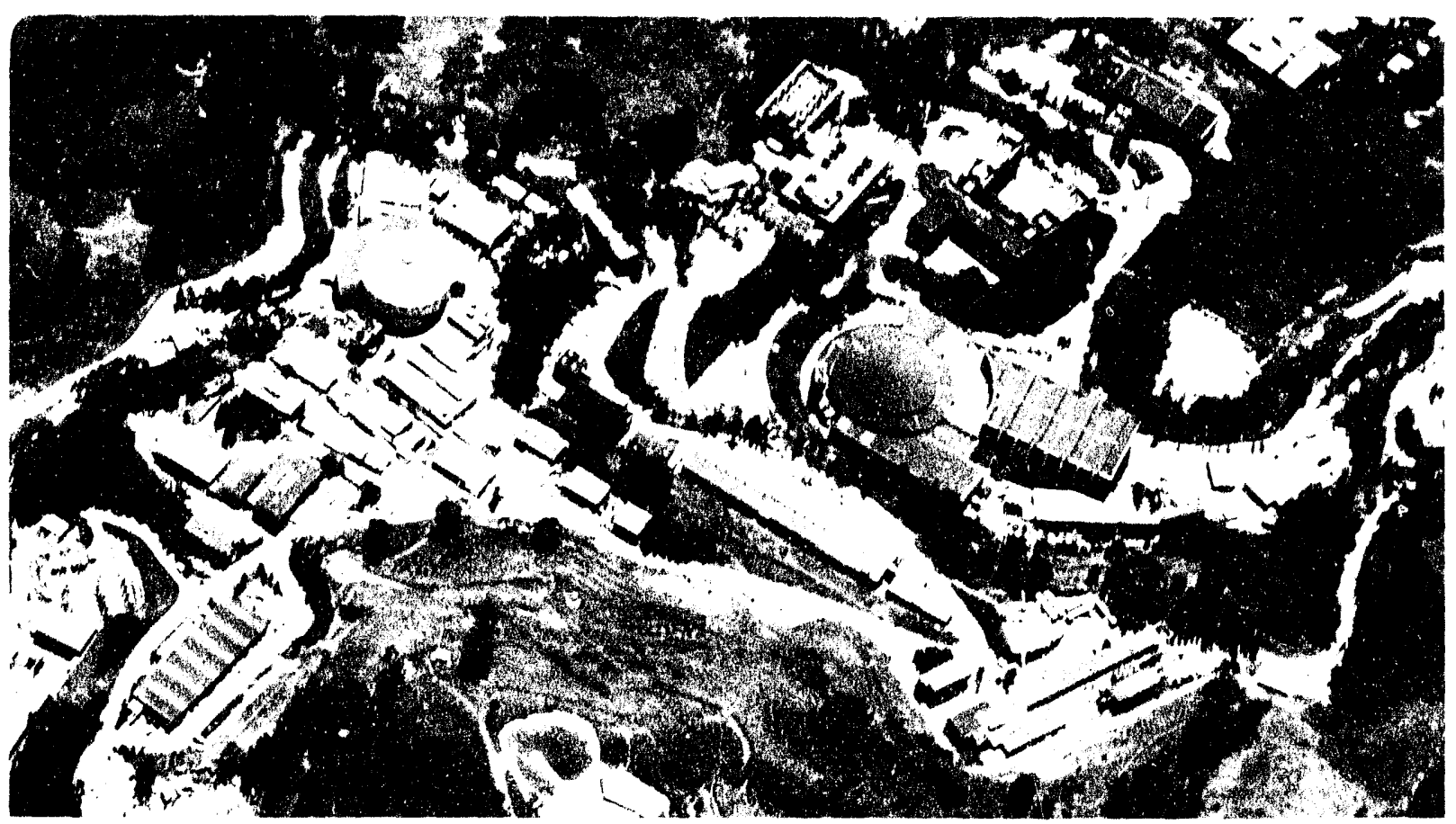

Prepared for the U.S. Department $0^{\curvearrowleft}$ Energy under Contract Number DE-AC03-76SF00098 


\section{DISCLAIMER}

This document was prepared as an account of work sponsored by the United States Government. Neither the United States Government nor any agency thereof, nor The Regents of the University of California, nor any of their employees, makes any warranty, express or implied, or assumes any legal liability or responsibility for the accuracy, completeness, or usefulness of any information, apparatus, product, or process disclosed, or represents that its use would not infringe privately owned rights. Reference herein to any specific commercial product, process, or service by its trade name, trademark, manufacturer, or otherwise, does not necessarily constitute or imply its endorsement, recommendation, or favoring by the United States Government or any agency thereof, or The Regents of the Univ. . y of California. The views and opinions of authors expressed herein do not necessarily state or reflect those of the United States Government or any agency thereof or The Regents of the University of California and shall not be used for advertising or product endorsement purposes.

Lawrence Berkeley Laboratory is an equal opportunity employer. 


\title{
AMORPHOUS SILICON PIXEL LAYERS WITH CESIUM IODIDE CONVERTERS FOR MEDICAL RADIOGRAPHY
}

\author{
T. Jing, C. A. Goodman*, G. Cho, J. Drewery, W.S. Hong, H. Lee, S. N. \\ Kaplan, A. Mireshghi, V. Perez-Mendez, D. Wildermuth* \\ Lawrence Berkeley Laboratory \\ University of California \\ Berkeley, CA 94720 \\ *Air Techniques, Inc., Hicksville, NY 11802
}

\begin{abstract}
We describe the properties of evaporated layers of Cesium Iodide (Thallium activated) deposited on substrates that enable easy coupling to amorphous silicon pixel arrays. The CsI(Tl) layers range in thickness from 65 to $220 \mu \mathrm{m}$. We used the two-boat evaporator system to deposit CsI(Tl) layers. This system ensures the formation of the scintillator film with homogenous thallium concentration which is essential for optimizing the scintillation light emission efficiency. The $\mathrm{Tl}$ concentration was kept to $0.1-0.2$ mole percent for the highest light output. Temperature annealing can affect the microstructure as well as light output of the CsI(Tl) film. 200-300C temperature annealing can increase the light output by a factor of two. The amorphous silicon pixel arrays are $\mathrm{p}-\mathrm{i}-\mathrm{n}$ diodes approximately $1 \mu \mathrm{m}$ thick with transparent electrodes to enable them to detect the scintillation light produced by X-rays incident on the CsI(Tl). Digital radiography requires a good spatial resolution. This is accomplished by making the detector pixel size less then $50 \mu \mathrm{m}$. The light emission from the $\mathrm{CsI}(\mathrm{Tl})$ is collimated by techniques involving the deposition process on pattered substrates. We have measured MTF of greater than 12 line pairs per $\mathrm{mm}$ at the $10 \%$ level.
\end{abstract}

This work was supported by the Director, Office of Energy Research, Office of High Energy and Nuclear Physics, Division of High Energy Physics, of the U.S. Department of Energy under Contract No. DE-AC03-76SF00098. 


\section{INTRODUCTION}

A variety of techniques are presently avaiiable for $x$-ray imaging. One common technique employs an $\mathrm{x}$-ray absorbing phosphor screen which emits optical radiation which exposes photographic film held adjacent the phosphor screen. This technique offers the advantage of high resolution, but is not effective for real time imaging because of the need to develop the film to obtain a visible image. Another alternative is the use of $x$-ray image intensifiers which are also generally used in digital radiography at present. While this system operates in real time, it suffers from the disadvantage that it produces relatively low resolution images as a result of optical scattering, imperfect electron optics, loss of sharpness in the optics coupling the image intensifier to the camera and other causes. In addition, it is bulky, fragile and expensive. Thus there is a need for alternative technologies in modern radiological imaging, particularly in digital radiography.

Semiconductor photosensitive imaging arrays are widely available today. These detector arrays, such as, charge coupled devices (CCD) and $p-n$ junction silicon diode arrays are limited to small array area less than $3 \times 5 \mathrm{~cm}^{2}$ which restrict their application for most medical radiation imaging[1,2]. These solid state arrays are capable of providing high resolution conversion of visible light images to electronic form. Unfortunately these arrays do not respond effectively to $\mathrm{x}$-ray radiation. Thus a mediating $x$-ray sensitive scintillator is necessary to convert the radiation to visible light. However, a degree of diffusion of the luminescent photns occurs in the scintillator layer as a consequence of which the modulation transfer function (MTF) deteriorates for the detected $x$-ray image[3].

In recent years, our group has begun to study the use of a new silicon alloy, hydrogenated amorphous silicon (a-Si:H), as a radiation detector[4-6], which has the merit of good radiation hardness due to its random structure and can be fabricated in large area inexpensively. A matrix of position-sensitive a-Si:H pixels in conjunction with an array of thin film transistor (TFT) amplifiers and readout electronics (Fig.1) may be considered as an alternative to detect radiation imaging with better spatial resolution, large sensitive area and lower cost than conventional devices. In Fig. 1, the sensor photodiodes are made of a- 
Si:H. The readouts are TFT fabricated from polycrystalline silicon which can be crystallized from a-Si:H on the same substrate[7].

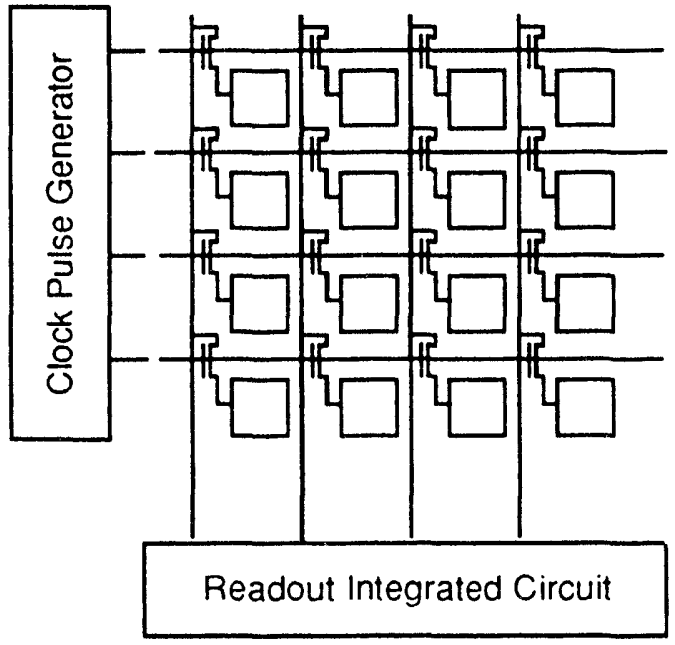

(a)

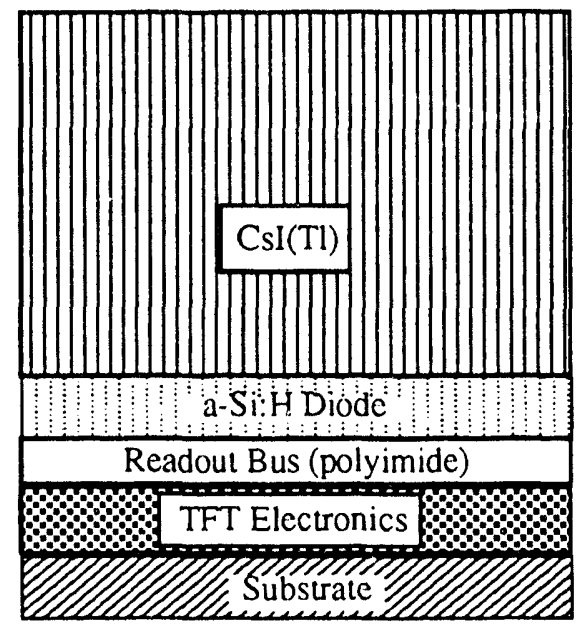

(b)

Fig.1 (a) Schematic diagram of a-Si:H pixel detector, (b) Structure of a single element of the detector

Choice of a scintillator dependents on specific requirements for each detector application, namely, the type of radiation, speed requirement and spatial resolution. $\mathrm{CsI}(\mathrm{Tl})$, known as a most efficient scintillator for $\mathrm{x}$-ray radiation, can produce 63,800 photons/Mev absorbed under optimal conditions $[8,9]$. Moreover, the emission spectrum of $\mathrm{CsI}(\mathrm{Tl})$ is a good match to a-Si:H photodiode[10]. Thus the combination of CsI(Tl) layer with a-Si:H diode pixel arrays is a good choice for large area, low cost, sensitive 2-D radiation detectors.

Since light spread inside a scintillator degrades the spatial resolution of a position sensitive detector, a fast bright scintillator with some built-in light guiding structure is desirable[11]. In this paper, we present a new approach for the fabrication of a CSI(Tl) layer by forming a sequence of columns of regular, controlled size (diameter) perpendicular to the substrate (or detector), which endows the scintillator with a light collimating structure, thereby improving the resolution of the radiation detection. The preparation and morphology of CsI on patterned substrates are described in the next section. The measurements and properties of evaporated CSI(TI) layers, such as light yield, decay time and light spread inside scintillation layers are discussed. 


\section{PREPARATION OF THE CsI(TI) FILM}

\section{A. Substrate Patterning}

In order to optimize the scintillator microstructure the CSI was deposited on various patterned substrates. The following procedure is the preferred one for creating a topographical surface comprising a plurality of individual islands that are spaced apart by intervening grooves. As a substrate we use $\mathrm{Si}$ wafers (for dicing convenience) which was dehydrated in order to prevent the formation of bubbles inside a following coated polyimide layer. The photosensitive polyimide $\mathrm{Du}$ Pont PI 2722, which is a soluble polyimide precursor containing photosensitive materials, was spin-coated on the substrate surface to produce a polyimide layer of $\sim 10-15 \mu \mathrm{m}$ thick. After proper soft bake, the polyimide film was directly patterned by standard photolithography techniques. The exposed polyimide film was then etched and well rinsed by Du Pont DP 6018 etchant, RI 9045 rinse solvent. The patterned layer was cured at $120 \mathrm{C}^{\circ}$ to $400^{\circ}$ and is shown in Fig.2. The CsI was vacuum evaporated on to the patterned wafer.

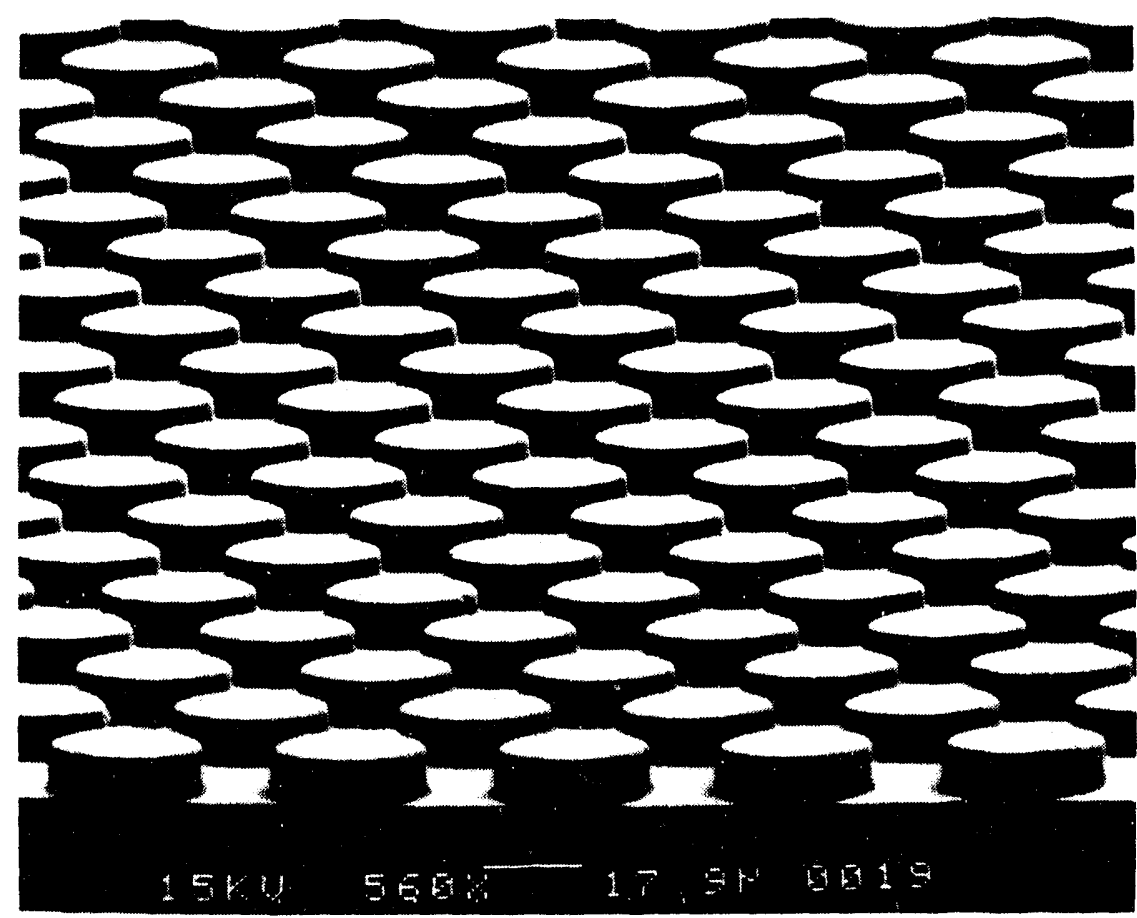

Fig.2 SEM of the patterned substrate 
Another scheme is the formation of cap-like patterns which is undercut by the etching process. This patterned substrate produces the same preferably growing sites for CsI deposition. In addition, the undercut part below the cap forms a path that allows liquid to fill into the grooves easily and further fill up to the gaps between the columns by capillary phenomenon. If the liquid is volatile and contains opaque material, after evaporating the liquid, the solute in the liquid will remain in the gaps or on the surface of the columns, hence the side-scattering light is further blocked. For this we used $\mathrm{Si}$ wafers which were thermally oxidized to form $1-2 \mu \mathrm{m}$ thick $\mathrm{SiO}_{2}$ film as a protection mask. The $\mathrm{SiO}_{2}$ film was patterned by photolithography techniques. Then the unprotected part of the $\mathrm{Si}$ was plasma etched with a SF6/He gas mixture at a ratio of $2: 1$ under $160 \mathrm{mTorr}$ at the power density of $80 \mathrm{~mW} / \mathrm{cm}^{2}$ for 25 minutes. The caps are about $33 \mu \mathrm{m}$ in diameter, $15 \mu \mathrm{m}$ in height and $40 \mu \mathrm{m}$ center-to-center spacing.

\section{B. Deposition of $C s l(T l)$}

The deposition rate and substrate temperature were found to be factors which affect the signal yield from CsI layer[5]. The high light yield was obtained at a low deposition rate $<3 \mu \mathrm{m} / \mathrm{min}$ and a substrate temperature of $100 \mathrm{C}^{0}-150 \mathrm{C}^{0}$.

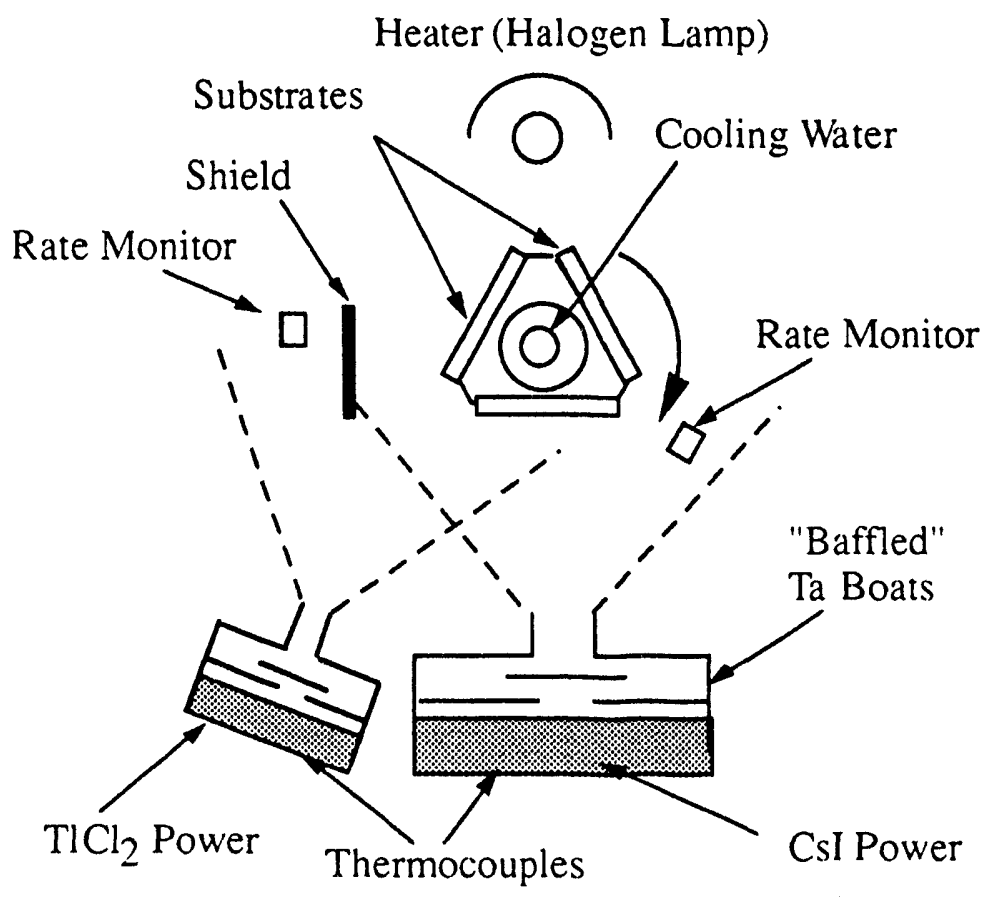


$t$ is difficult using conventional evaporation techniques to make deposits having the same composition as the source material when the vapor pressures of the constituents $\mathrm{Tl}$ and $\mathrm{CsI}$ are dramatically different[12]. The vacuum evaporation setup at LBL is shown schematically in Fig. 3 , which is designed to avoid the above-mentioned problem by using two boats to evaporate CsI and dopant $\mathrm{TlI}_{2}$ separately. The substrates were mounted above the evaporation boat chimney. The Halogen lamp above the holder supplies the radiant heat to maintain the substrate temperature. In the evaporation process, vapors emanate from a CsI source located in a boat that is heated by direct resistance. When the vapors condense into a solid phase, the latent heat of vaporization will be released, which will cause the substrate temperature to increase. To compensate this temperature increase, the substrate holder was cooled by a water tubing system. The two boats were operated at different temperature according to the desired composition radio of $\mathrm{Tl}$ to $\mathrm{CsI}$ inside the scintillator. The two rate monitors were placed in each side to monitor the deposition rates of the two sources. In this way, a fixed ratio of CSI to $\mathrm{Tl}$ was obtained, i.e., the scintillator layer was made with homogeneous thallium concentration to obtain the highest light yield. Use of this double evaporator incresed the scintillation light yield by $\sim 30 \%$.

\section{Microstructure of the deposited CsI(Tl) film}

Microstructure of the deposited layer is determined by nucleation and growth of film from the depositing atoms. Nucleation of the depositing atoms will depend on the atom-substrate interactions and the surface mobility of the depositing atoms[13]. 

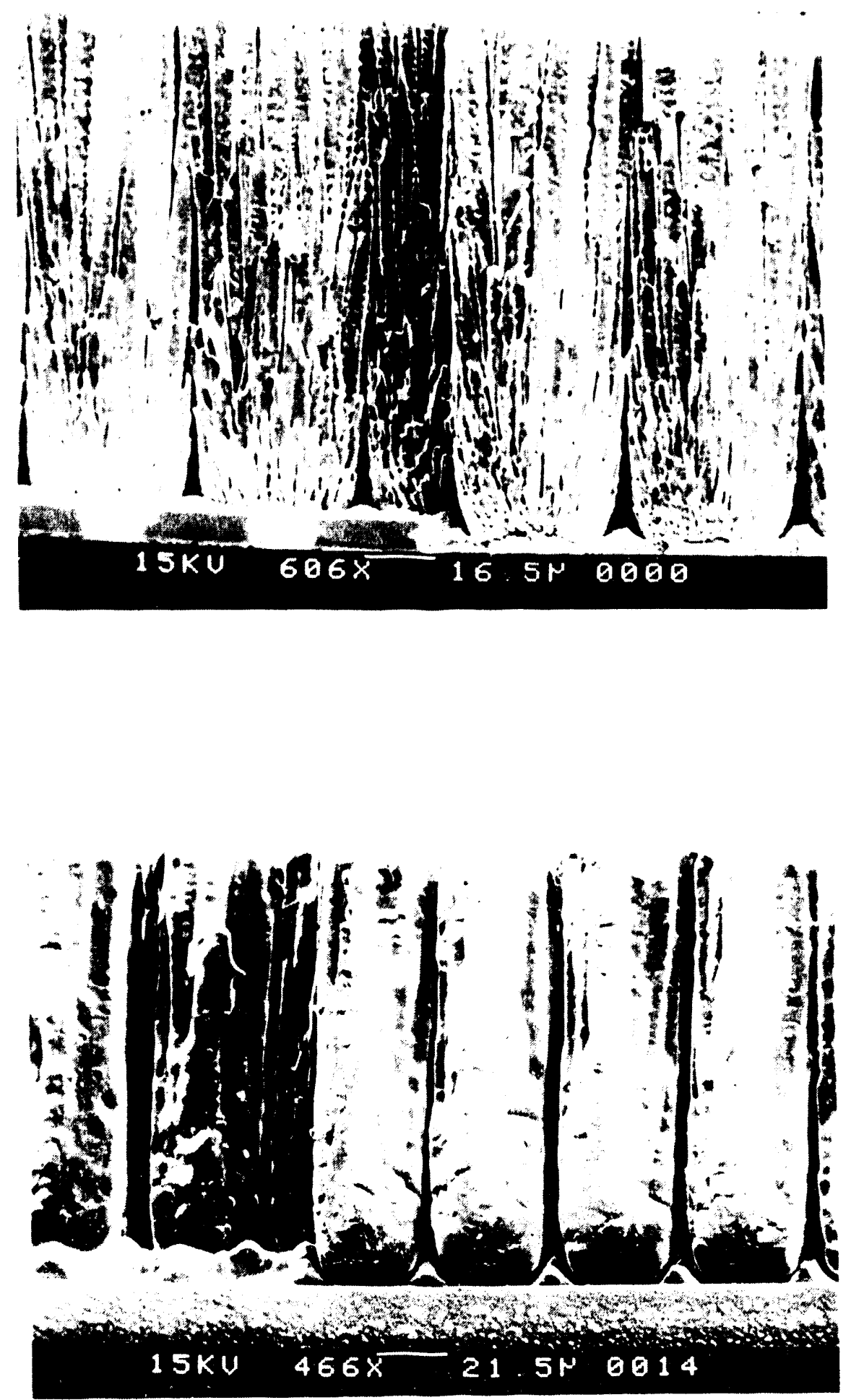

Fig. 4(a) SEM C'sI(Tl) layer on patterned substrate (b) SEM CsI(Tl) layer after annealing 
Since the CsI vapor atoms will initially interact with the raised portions (pucks) on the substrate, the deposited atoms are preferentially nucleated. By maintaining appropriate substrate temperature to control the surface mobility of the deposited atoms, the further growth can be oriented by the initial nucleation. As shown in Fig. , columns are formed following the substrate patterns. Each column is composed of many pillar-like crystals of several microns diameter grown almost perpendicularly from substrate, as shown in Fig. 4a. It should be noticed that as the deposition continues there is a tendency for the columns to widen or spread especially near the top, and finally to close the gap between the two adjacent columns. To reduce this spreading effect at the columns, as well as to increase somewhat the spacing between adjacent columns, the sample was annealed at $500 \mathrm{C}^{0}$ for a period of about 30 minutes. Such heat treatment causes the CsI in the column to become compacted by forming more perfect grains through recrystallization, so that the diameters of the columns decrease as seen in Fig. $4 \mathrm{~b}$

\section{PERFORMANCE OF THE CsI(Tl) FILM}

\section{A. Light output vs Tl concentration}

The $\mathrm{Cl}$ concentration is known to affect the light yield in crystalline bulk crystalline $\mathrm{Cs}(\mathrm{Tl})$ [14]. A concentration of 0.1-0.2 mole percentage is required for an optimal light output[15]. The $\mathrm{Tl}$ concentrations in the evaporated layers were evaluated by Reflection Fluorescence analysis (XRF)[16]. The scintillation light output was measured using a Hamamatsu S1732-04 silicon photodiode coupled to the CsI(Tl) film. The light output was measured in terms of the number of photoelectrons produced on the photodiode per Mev of energy deposited in the CsI(Tl) film by a calibrated $50 \mathrm{KVp} \times$-ray source. The light yields were plotted against the $\mathrm{Tl}$ concentration as shown in Fig.5. This graph indicates that for a good light yield, the $\mathrm{Tl}$ concentration should not be less than 0.02 mole percentage. 


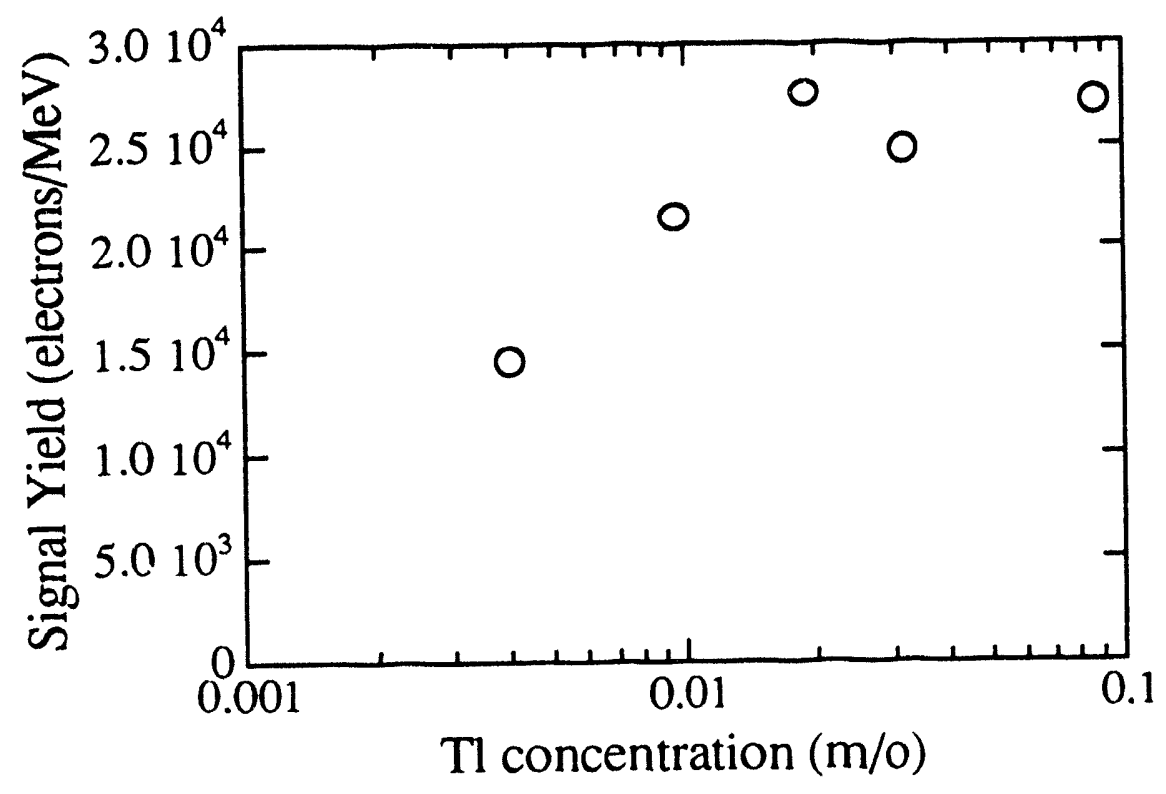

Fig. 5. Light yield vs $\mathrm{Tl}$ concentration

\section{$B$. The effect of the heat treatment}

The heat treatment of the CsI layer, not only changes its morphological structure but also affects the light emission efficiency. CsI samples were annealed at temperatures $200 \mathrm{C}^{0}$ to $500 \mathrm{C}^{0}$ for 30 minutes. The light output systematically increases with increasing the annealing temperature. As seen in Fig. 6, the initial annealing (from $150 \mathrm{C}^{0}$ to $250 \mathrm{C}^{0}$ ) causes a larger increase in the light yield than the higher temperature annealing. This light output effect of the heat treatment indicates that the annealing can cause the $\mathrm{Tl}$ atoms to relocate in the CsI by thermal diffusion processes, which therefore create more $\mathrm{Tl}+$ luminescent centers and thus more effectively activate the CsI to emit the light. In addition, it should be emphasized that at the temperatures beyond $550 \mathrm{C}^{0}$ the annealing will degrade the CsI light yield because some of $\mathrm{Tl}$ atoms will escape from CsI surface due to the high equilibrium vapor pressure of the Tl. 


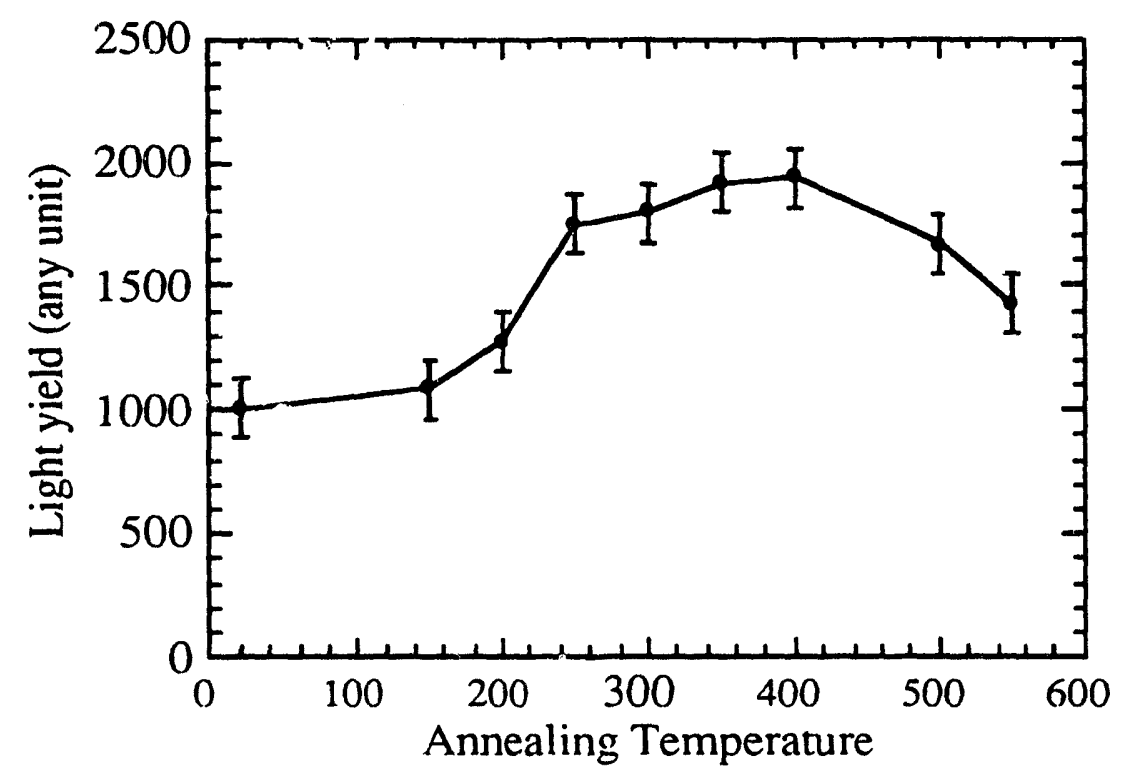

Fig. 6 Light yield vs annealing temperature

\section{Radiation Resistance of the bulk and film CsI}

A scintillation screen, as the input radiation converter, absorbs most of the incoming radiation energy during long term medical imaging or high rate particle detection. It will undergo radiation damage, thereby decreasing the light yield. Thus there is concern over the sensitivity of the CsI(Tl) film which may limit its use in stable radiation detection, because previous data[17,18] has shown that the pulse height reduction from bulk CsI(Tl) is already significant at a dose level of $1 \mathrm{~Gy}$. We exposed an evaporated $\mathrm{CsI}(\mathrm{Tl})$ layer $125 \mu \mathrm{m}$ thick to various dose levels to determine its radiation tolerance. The irradiation was done with a strong $\gamma$-ray Co-60 source at the irradiation facility at $\mathrm{LBL}$. The nominal activity of the $\mathrm{C} 0-60$ source was $6000 \mathrm{Ci}$. The CsI sample was placed at calibrated positions $10-30 \mathrm{~cm}$ away from $\mathrm{Co}-60$ source. An ion chamber detector was used to monitor the dose which determined the exposure time required for the total dose. The signal yield was measured after each exposure. It was normalized relative to its original signal output. Fig.7 also shown the data for a $1 \mathrm{~cm}$ thick crystal CsI(Ti) taken from ref[19]. 


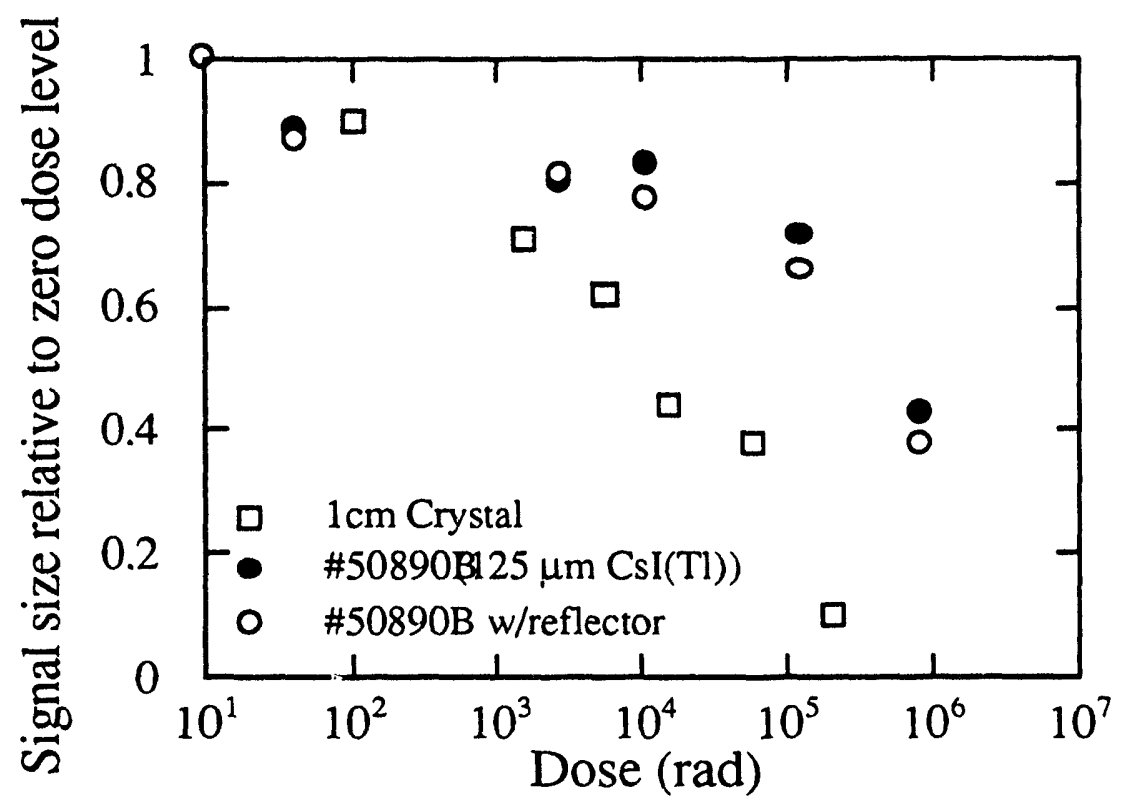

Fig. 7 Radiation resistance

As shown in Fig. , the dose required to reduce the signa! size by a factor of two for this evaporated layer is about 50 times larger than that for $1 \mathrm{~cm}$ thick bulk CsI sample. The signal loss is systematically larger when the light collection is improved by the $\mathrm{Al}$ reflector. This suggests that the radiation damage changed optical transmission properties of the scintillator, in agreement with more detailed studies on crystal CsI[19].

Generally, there are two origins for radiation damage in CsI[19]. One is the intrinsic origin which causes coloration due to the F-center (a negative ion vacancy with one excess electron bound at the vacancy) and to other more complicated color centers. The other is extrinsic, which causes coloration and afterglow due to impurities. Both cause transmission loss of the scintillation light. Recovery from radiation damage, both transmission and light output, has been studied extensively[20,21]. A small amount of natural recovery was observed in CsI kept in the dark at room temperature for a period 30 days. Very little recovery was observed with exposure to UV light[20]. However, the quick damage recovery was reported by exposure to sunlight[19]. 


\section{Fluorescence Decay Time}

CsI and CsI(Tl) film with different $\mathrm{Tl}$ concentration were deposited by evaporation. The light yield timing spectra were measured by a table-top pulse $\mathrm{x}$-ray system with a timing accuracy of about $100 \mathrm{ps,} \mathrm{which} \mathrm{combined} \mathrm{a} \mathrm{state-}$ of-the-art laser diode and a light-excited $x$-ray tube. The details of this system can be found in ref[22]. Analysis of the decay spectra of the bulk CsI(Tl) crystal which is the source material for the deposited CsI layer resulted in three decay periods: $900 \mathrm{~ns}, 1500 \mathrm{~ns}$, and $3500 \mathrm{~ns}$. The fast component dominates the total light yield. The rise time of the light peak can be easily found at $80 \mathrm{~ns}$ by expanding the time scale of Fig.8a. For the layers made from the above crystal with different $\mathrm{Tl}$ concentrations, the three decay components are still found with the same relative amplitudes, which are independent of $\mathrm{Tl}$ concentration. The ultrafast components were clearly observed in these evaporated layers, with intensities which are correlated with the $\mathrm{Tl}$ concentration. Fig. $8 \mathrm{~b}$ shown the light yield spectra of the evaporated layers at the $\mathrm{Tl}$ concentrations of 0.3 mole percentage and 0.6 mole percentage. The amplitude of the ultrafast component of the sample with less $\mathrm{Tl}$ is larger than that of higher $\mathrm{Tl}$ one and has two components roughly $\mathrm{t} 1=2 \mathrm{~ns}, \mathrm{t} 2=6 \mathrm{~ns}$. The reason for the appearance of this unique ultrafast component in the evaporated layer may be due to the redistribution of the $\mathrm{Tl}+$ luminescent center during the fabricating process of the layer.

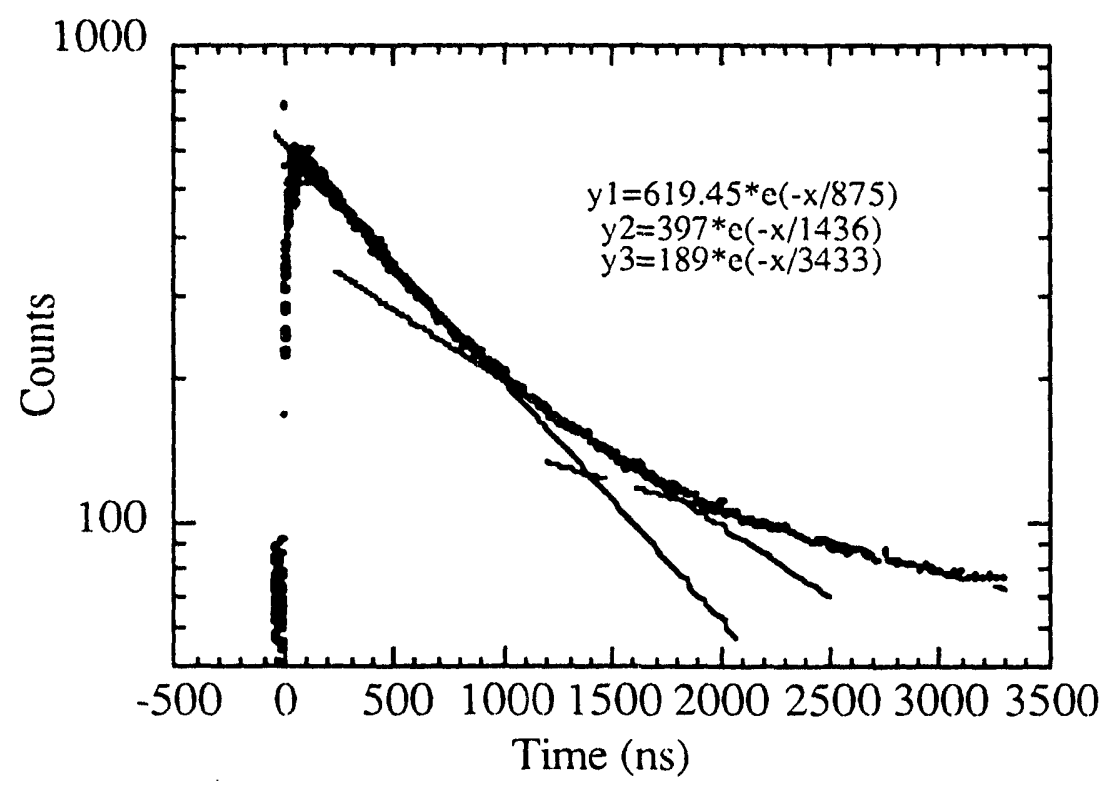




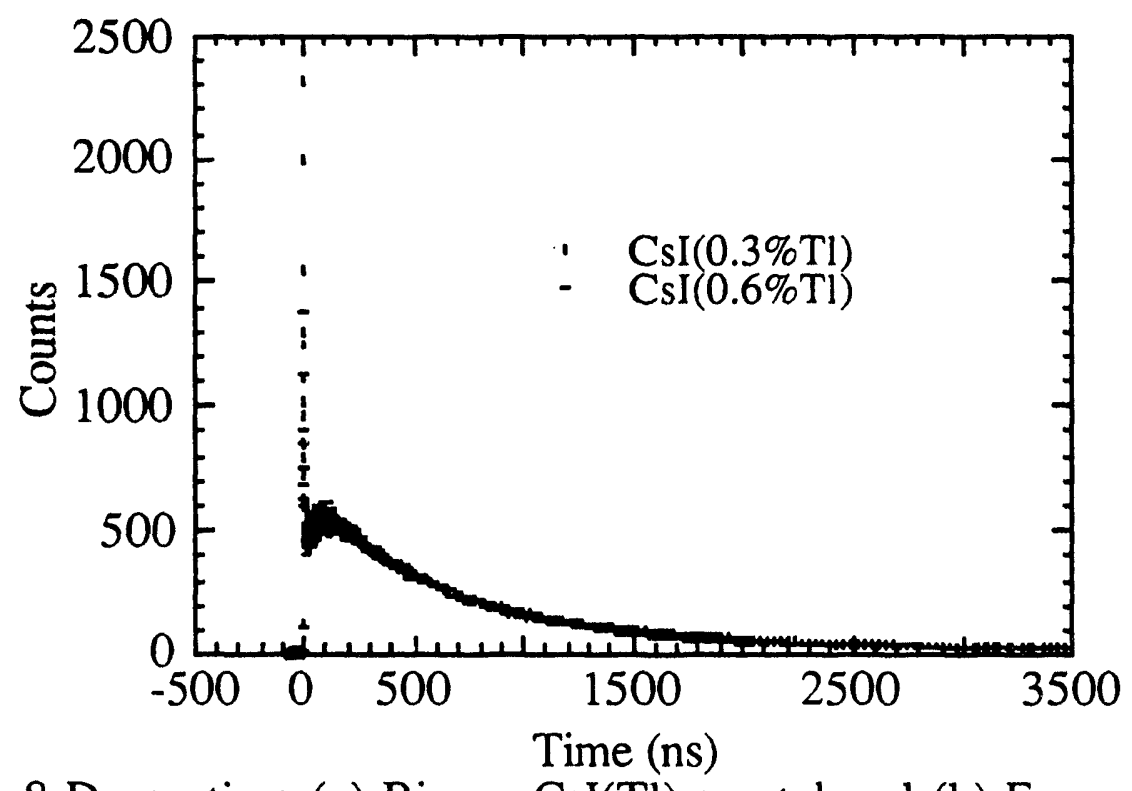

Fig. 8 Decay time (a) Bicron CsI(Tl) crystal and (b) Evaporated CsI(Tl) layers with $\mathrm{Tl}$ concentration of 0.3 mole\% and 0.6 mole \%

\section{E. Spatial Resolution}

The CsI screen spatial resolution was evaluated by measuring its line spread function (LSF). The scintillation light spread from evaporated CsI(TI) layers (various thicknesses) was characterized by exposing a scintillator to a narrow beam of $\mathrm{X}$-rays and detecting the light output with a position sensitive detector. The low energy $\mathrm{x}$-ray beam was generated by an $\mathrm{x}$-ray tube operated at $49 \mathrm{KVp}$ and viewed through a $25 \mu \mathrm{m}$ wide slit. The penetration depth is small enough so that the most of the irradiation energy could be deposited inside the CsI(TI) film. A linear silicon photodiode array (EG\&G Reticon RL0256SBU-001) was used as the light sensor and it had 20 dots $/ \mathrm{mm}$ resolution. The output signals were digitized and stored in a computer for further analysis. The line spread function for each scintillator was obtained by this method. Fig. 9 gives the LSF of Kodak Lanex Screens and CsI layers. The curve a shows the LSF of Lanex Fast Screen $288 \mathrm{~mm}$ thick, curve (b) that of non-structured CsI(Tl) crystal layer $220 \mu \mathrm{m}$ which exhibits a longer tail than curve (a) due to its good light transmission and curve (c) that of structured CsI(Tl) layer $220 \mu \mathrm{m}$ thick with the same light emission efficiency as the Lanex fast screen. The structured CsI(Tl) layer substantially suppressed its light spread by its lauto-collimating structure. Thus it exhibits a narrower LSF that is superior to the Lanex fast screen and the 
non-structure CsI layer. Curves (d) and (e) are the same thickness $75 \mu \mathrm{m}$ scintillators, Lanex fine screen and structured CsI(Tl) layer. Again, the structured $\mathrm{CsI}(\mathrm{Tl})$ layer has a higher resolution than the Lanex screen. The comparison of characteristics of $\mathrm{CsI}(\mathrm{Tl})$ layers with Lanex screens are summarized in Table I.

Table I Comparision of Characteristics of CsI(Tl) Layers with Lanex Screens

\begin{tabular}{|l|l|l|l|l|}
\hline Scintillators & $\begin{array}{l}\text { Relat } \\
\text { ive } \\
\text { Light }\end{array}$ & $\begin{array}{l}\text { Spati } \\
\text { al }\end{array}$ & $\begin{array}{l}\text { MTF } \\
\text { at } 10\end{array}$ & $\begin{array}{l}\text { Thic } \\
\text { knes } \\
\text { s }\end{array}$ \\
\hline $\begin{array}{l}\text { Lanex Fine } \\
\text { Screen }\end{array}$ & 100 & 96 & 9.1 & 75 \\
$\begin{array}{l}\text { Structured } \\
\text { CsI(Tl) Layer }\end{array}$ & 120 & 69 & 15.9 & 65 \\
$\begin{array}{l}\text { Structured } \\
\text { CsI(TI) Layer }\end{array}$ & 170 & 81 & 12.0 & 75 \\
$\begin{array}{l}\text { Structured } \\
\text { CsI(TI) Layer }\end{array}$ & 226 & 98 & 9.0 & 112 \\
$\begin{array}{l}\text { Lanex Medium } \\
\text { Screen }\end{array}$ & 210 & 179 & 4.6 & 140 \\
$\begin{array}{l}\text { Non-structured } \\
\text { CsI }\end{array}$ & 396 & 198 & 3.2 & 190 \\
$\begin{array}{l}\text { Structured } \\
\text { CsI(Tl) Layer }\end{array}$ & 340 & 110 & 8.0 & 144 \\
$\begin{array}{l}\text { Lanex Fast } \\
\text { Screen }\end{array}$ & 520 & 330 & 2.5 & 288 \\
$\begin{array}{l}\text { Non-structured } \\
\text { CsI }\end{array}$ & 410 & 259 & 2.9 & 220 \\
$\begin{array}{l}\text { Structured } \\
\text { CsI(TI) Layer }\end{array}$ & 620 & 173 & 5.3 & 220 \\
\hline \hline
\end{tabular}




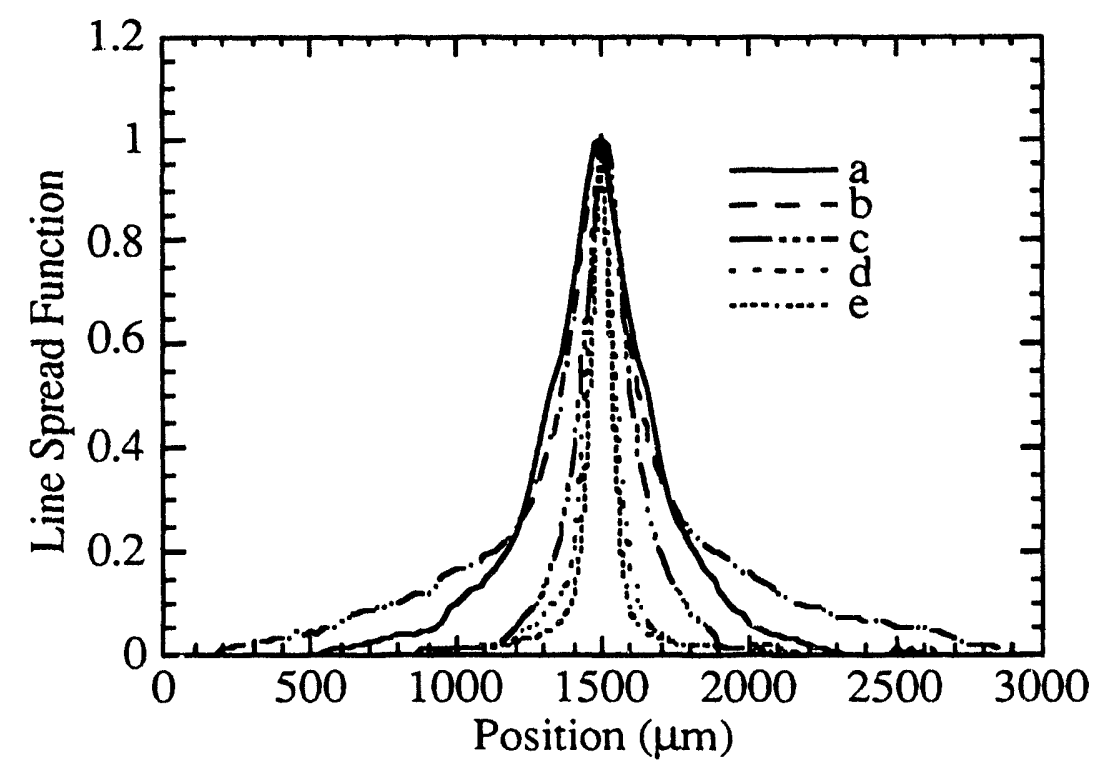

Fig. 9 LSF of Lanex and CsI: (a) Lanex Fast Screen, (b) Non-structured CsI(Tl) crystal $220 \mu \mathrm{m}$ thick, (c) Structured CsI(Tl) layer $220 \mu \mathrm{m}$ thick, (d) Lanex fine Screen $75 \mu \mathrm{m}$ thick and (e) Structured CsI(Tl) layer $75 \mu \mathrm{m}$ thick

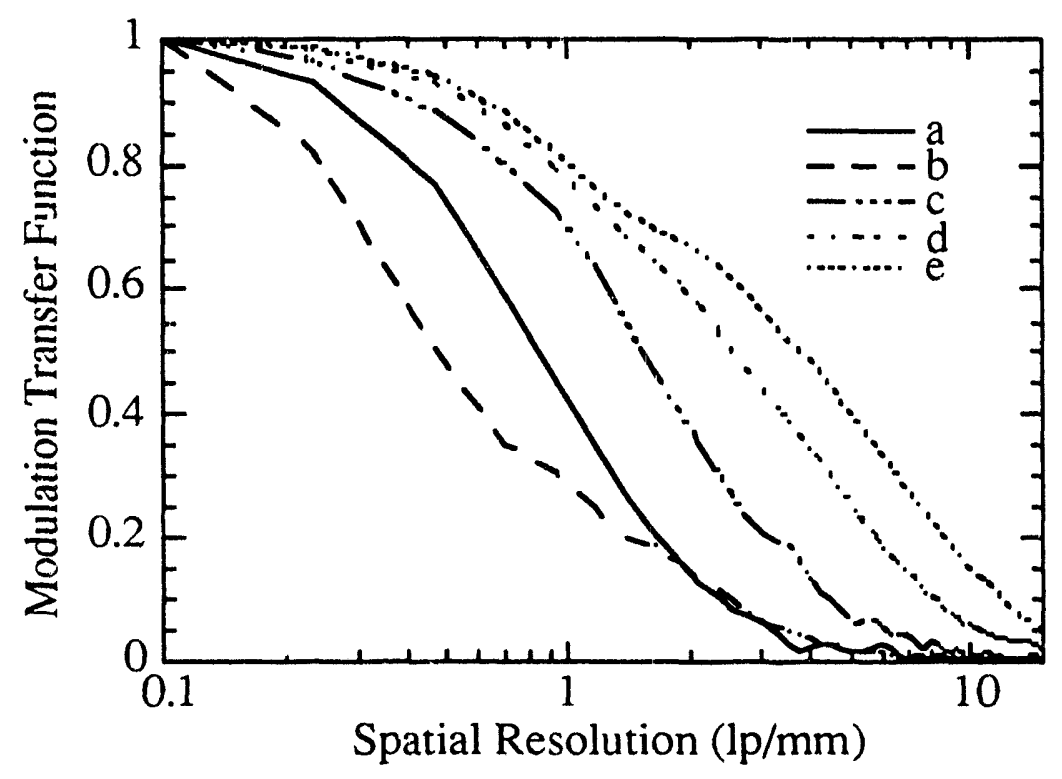

Fig. 10 MTF calculated from LSF in Fig.9 
The MTF was determined by Fourier analysis of LSF. The MTF of the scintillation screen was obtained from MTFtot by correcting the MTF losses due to the limited width of the $x$-ray beam and the finite pixel size. The MTFs of the scintillation screens were normalized to unity at zero spatial frequency. The data of Fig. 10 show the MTFs corresponding to the LSFs in Fig.9. Curves (a) and (b) exhibit the same MTF at the high frequency portion. The effect of reducing amplitude at the low frequency portion of MTF of non-structured $\mathrm{CsI}(\mathrm{Tl})$ is mainly due to its wider lighi spread tail. The structured CsI(Tl) curve (c) showed substantial improvement of MTF over curves (a) and (b) at all spatial frequencies. Curve (e) (structured CsI layer) has a spatial resolution at $10 \%$ level of up to $12 \mathrm{lp} / \mathrm{mm}$, while the Lanex fine screen has a spatial resolution 9.1 $\mathrm{lp} / \mathrm{mm}$ at the same level. Further this CsI(Tl) layer has better light yield efficiency, see Table 1 . 


\section{CONCLUSION}

Owing to the structure of the $\mathrm{CsI}(\mathrm{Tl})$ layers, it is possible to use a thicker scintillator layer for achieving higher $\mathrm{x}$-ray absorption without the attendant degradation of resolution. A structured $\mathrm{CsI}(\mathrm{Tl})$ layer $\sim 110 \mu \mathrm{m}$ thick produces twice as much light as a Kodak Lanex Fine screen with the equivalent resolution. Hence $\mathrm{x}$-ray imaging can be carried out with smaller radiation doses. This is obviously advantageous for the patient. The performance of an $x$-ray imaging system is predominately determined by the input screen converters for the whole range of spatial frequencies which are of practical interest. This makes the CsI screen one of the most essential components in a radiographic imaging system. A minimum $\mathrm{Tl}$ concentration of 0.02 mole is required for an optimal light yield. The evaporated $\mathrm{CsI}(\mathrm{Tl})$ layer is more resistant to radiation damage than a CsI crystal; its light output is reduced by a factor of two after $10^{4}$ Gy exposure. The fluorescent time is predominately within $3 \mu$ s for the doped CsI layer. The ultrafast component of the light yield can be enhanced by incorporating less $\mathrm{Tl}$ dopant. The measurements and analysis have shown that structured $\mathrm{CsI}(\mathrm{Tl})$ layers coupled to a-Si:H pixel arrays or other sensor arrays are good candidates for detectors in 2-dimensional imaging detection.

\section{ACKNOWLEDGEMENTS}

The authors wish to express their appreciation to Dr. G. Weckler of EG\&E for providing us photosensor arrays and their readout electronics. They are also grateful to Drs.S.E. Derenzo and W.W. Moses of LBL helping the decay time measurement. We also thank $\mathrm{Al}$ Lyons of $\mathrm{LBL}$ for depositing the CsI samples. 


\section{REFERENCES}

[1] M.G. Fedotov, E.A. Kuper and V.E. Panchenko," Peculiarities of CCD and Photodiode Arrays Application to X-ray Image," Nucl. Instr. and Meth. vol. 308, No. 10, 1991, pp. 367-371.

[2] H.F. Fuchs, D.Q. Qu and B. Chu," an Area X-ray Detector System Based on a Commercially Available CCD-unit," Rev. Sci. Instr. vol 61, No. 2, 1990, pp712-716.

[3] W. Hillen, W. Eckenbanch, P. Ouadfliey and T. Zaengel," Signal-ToNoise Performance in Cesium Iodiode X-ray Fluorescent Screens," Medical Imaging V, Proc. SPIE, vol. 1443, San Jose, California, Feb., 1991, pp. 120-131.

[4] V. Perez-Mendez, G. Cho, J. Drewery, T. Jing, S. N. Kaplan, S. Qureshi, and D. Wildermuth," Amorphous Silicon Based Detector," J. Non-crystalline Solids, vol. 137, No.12, 1991, 1291-1296.

[5] I. Fujieda, G. Cho, J. Drewery, T. Gee, T. Jing, S. N. Kaplan, V. PerezMendez, D. Wildermuth and R. A. Street," X-ray and Charged Particle Detection with CsI(TI) later Coupled to a-Si:H Photodiode layers," IEEE Trans. Nucl. Sci. vol. 38 , No. 2, 1991, pp. 255-262

[6] J.S. Drewery, G. Cho, I. Fujieda, T. Jing, S. N. Kaplan, V. Perez-Mendez, and D. Wildermuth,"Amorphous Silicon Pixel Arrays," Nucl. Instr. and Meth. vol. A310, 1991, pp. 165-170.

[7] G. Cho, J.S. Drewery, W.S. Hong, T. Jing, S. N. Kaplan, H. Lee, A. Mireshghi, V. Perez-Mendez, and D. Wildermuth," Signal Readout in a-Si:H Pixel Detector,".IEEE Trans. Nucl. Sci. vol. 40, No. 4, 1993, pp. 323-327.

[8] J. D. Valentine, D. K. Wehe, G. F. Knoll, and C. E. Moss," Temperature Dependence of CsI(Tl) Absolute Scintillation Yield," IEEE Trans. Nucl. Sci. vol. 40, No. 4, 1993, pp. 1267-1274.

[9] I. Holl, E. Lorenz, G. Mageras," A Measurement of the Light Yield of Common Inorganic Scintillators," IEEE Trans. Nucl. Sci. vol. 35, No. 1, 1988, pp. 105-109.

[10] H. Grassmann, E. Lorenz, and H. G. Moser," Properties of CsI(TI) Renaissance of an old scintillation material," Nucl. Instr. and Meth. vol. 228, 1985, pp. 323-326.

[11] T. Jing G. Cho, J. Drewery, I. Fujieda, S. N. Kaplan, A. Mireshghi, V. Perez-Mendez, and D. Wildermuth," Enhanced Columnar Structure in CsI Layer by Substrate Patterning," IEEE Trans. Nucl. Sci. vol. 39, No. 5, 1992, pp. 1195 1198. 
[12] J.A. Shepherd, S.E. Sobottka, and M.B. Williams," Performace and Fabrication of Thin Film NaI(Tl) Scintillators for Use on Imaging Photomultiplier Tubes," IEEE Trans. Nucl. Sci. vol. 40, No. 4, 1993, pp. 413-416.

[13] C.F. Powell, J.H. Oxley and J.M. Blocher,Jr. " Vapor Deposition," John Wiley \& Sons,Inc. 1966, pp. 173.

[14] J. B. Birks," The Theory and Practice of Scintillation Counting," Pergamom Press, 1964, pp. 436.

[15] P. Schotanus, R. Kamermans and P. Dorenbos," Scintillation Characteristics of Pure and Tl-doped CsI Crystal," IEEE Trans. Nucl. Sci. vol. 37, No. 2, 1990, pp. 177-182.

[16] R.D. Giauque, F.S. Goulding, J.M. Jaklevic and R.H. Pehl," Trace Element Determination with Semiconductor X-ray Spectrometers," Analytical Chemistry, vol. 45, 1973, pp. 671-681.

[17] C. Bieler, D. Burkart, J. Marks,M. Riebesell, H. Spitzer, K. Wittenburg and G.G. Winter," Radiation Damage of BGO and CsI(Tl) Crystals," Nucl. Instr. and Meth. vol. A234, 1985, pp. 435-442.

[18] S. Schlogl, H. Spitzer and K. Wittenburg," Radiation Damage of CsI(Tl) Crystals in a Long Term Exposure at Petra," Nucl. Instr. and Meth. vol. A242, 1985, pp. 89-94.

[19] M. Kobayashi, S. Sakuragi," Radiation Damage of CsI(Tl) Crystals above $10^{3}$ rad," Nucl. Instr. and Meth. vol. A254, 1987, pp. 275-280.

[20] C.L. Woody, J.A. Kierstead, P.W. Levy and S.Stoll," Radiation Damage in Undoped CsI abd CsI(Tl)," IEEE Trans. Nucl. Sci. vol. 39, No. 4, 1992, pp. 524-531.

[21] S.E. Derenzo, W.W. Moses, and S.C. Blankespoor," Design of a Pulsed X-ray System For Fluorescent Lifetime Measurements with a Timing Accuracy of 109 ps," IEEE Nucl. Sci. Symposium Record, 1992 

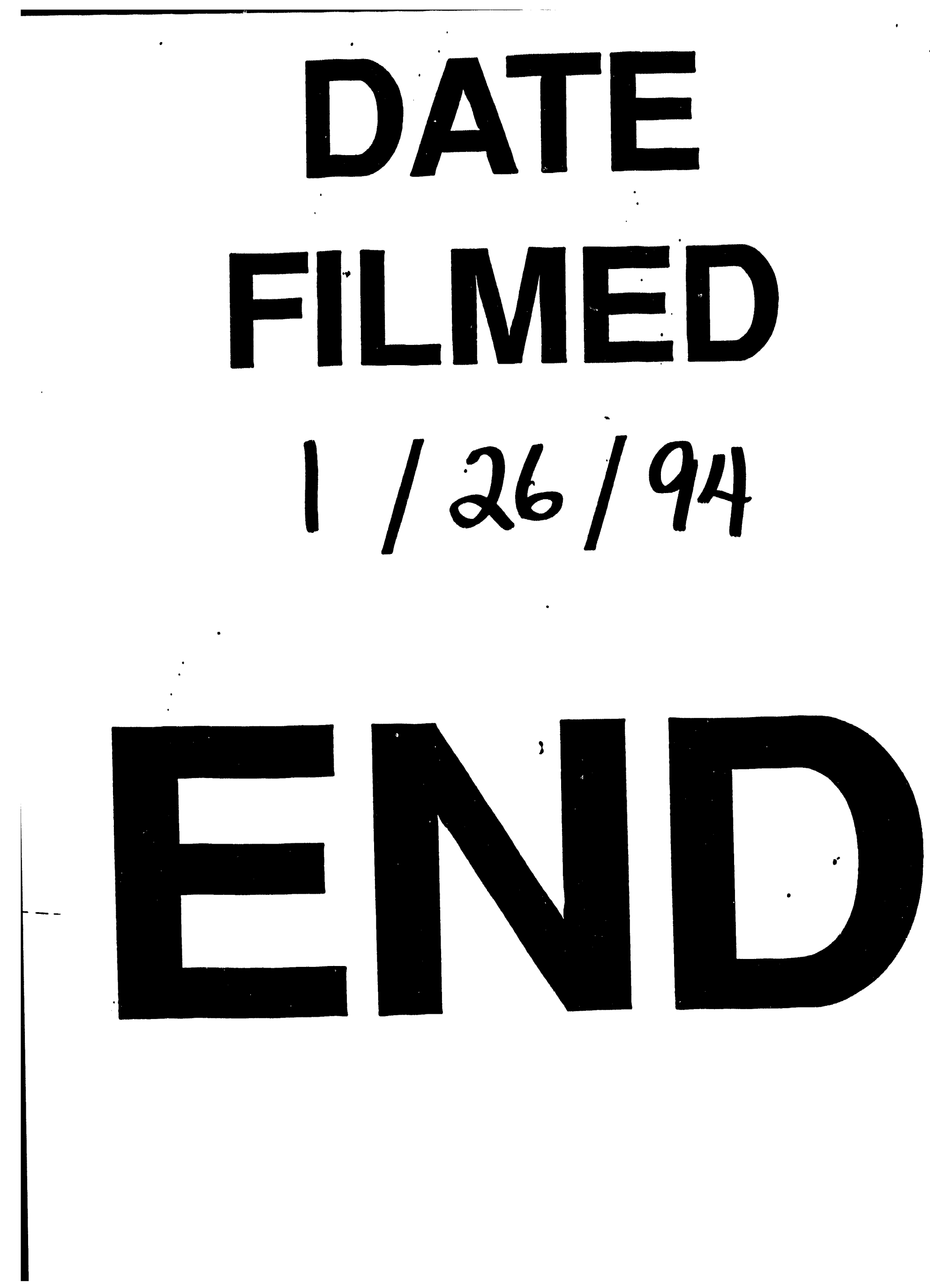
